\title{
Relationship between plasma cortisol level and bodyweight and antler size in farmed fallow deer
}

\author{
K. Dziki-Michalska ${ }^{1}$, K. Tajchman ${ }^{1 \#}$, S. Kowalik ${ }^{2}$ \& M. Bogdaszewski ${ }^{3}$ \\ ${ }^{1}$ Department of Animal Ethology and Wildlife Management, Faculty of Animal Sciences and Bioeconomy, University of \\ Life Sciences in Lublin, Akademicka 13, 20-950 Lublin, Poland \\ ${ }^{2}$ Department of Animal Physiology, Faculty of Veterinary Medicine, University of Life Sciences in Lublin, Akademicka 12, \\ 20-033 Lublin, Poland \\ ${ }^{3}$ Institute of Parasitology of the Polish Academy of Sciences, Research Station in Kosewo Górne, 11-700 Mrągowo, \\ Poland
}

(Received 19 November 2020; Accepted 16 March 2021; Published 21 May 2021)

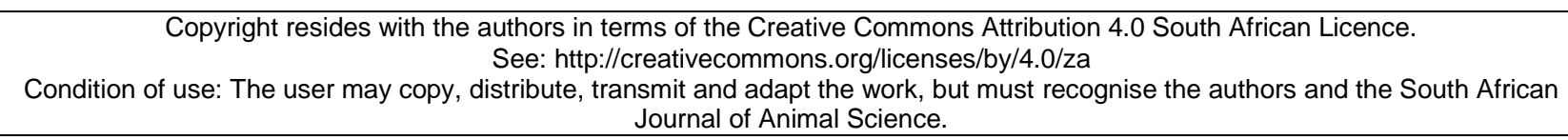
Journal of Animal Science.

\begin{abstract}
The aim of this study was to demonstrate the relationship between the plasma cortisol level and bodyweight and antler size in farmed male fallow deer (Dama dama) of various ages. The study involved 33 animals divided into three age groups: one year old, three years old, and older. Their bodyweight was measured and blood samples were taken twice a year during antler growth (May) and before the rut (September). Whole antlers were collected in September to measure their length and weight. The plasma cortisol concentration was determined with an immunoenzymatic method. The correlations between cortisol level and bodyweight were significant and positive in both May and September $(P \leq 0.05)$. There was a negative correlation between weight gain and change in cortisol levels $(P \leq 0.05)$. Thus, fallow deer with large seasonal changes in cortisol gained less weight from May to September. The results of the present study indicated that calmer animals with lower cortisol fluctuations should be selected for breeding, which would contribute to greater stability of weight gain.
\end{abstract}

Keywords: Dama dama, glucocorticoids, seasonal breeding, stress, veterinary treatments, weight gain \#Corresponding author: katarzyna.tajchman@up.lublin.pl

\section{Introduction}

Farm rearing of cervids has been developing in Europe and worldwide, albeit with varied intensity. However, cervids have different biological requirements and behavioural patterns, and are not as domesticated as typical livestock. For example, male cervids exhibit a sharp rise in aggressive behaviour during rut, which should be taken into account in their management to avoid potentially lethal fighting (Bartoš \& Bubenik, 2011). These animals have to be immobilized temporarily during deworming, marking, cutting antlers, health screening, and dividing into rearing groups,. This is usually performed twice a year before the grazing and winter seasons. At that time, the animals are driven from pastures into small manipulation pens. They are also immobilized inside handling boxes during these treatments, which are associated with exposure to high levels of stress (Mattiello, 2009; Janiszewski et al., 2016). Heightened stress levels tend to cause imbalances in hormones such as cortisol, dehydroepiandrosterone and adrenaline (Ranabir \& Reetu, 2011).

Cortisol is one of the universal markers of the magnitude of the stress response. Activation of the HPA axis causes an increase in the concentration of this hormone in the peripheral blood and saliva of animals exposed to a stressor (Smith \& Vale, 2006). An excess, or a deficiency, of cortisol can influence blood sugar levels and thyroid function, trigger changes in weight, and produce symptoms of low metabolism (Suttie et al., 1989; Dallman et al., 1995; Möstl \& Palme, 2002). Weight gain and loss are generally issues during elevated stress and afterwards. Animals that were not subject to stressors had lower cortisol levels than those exposed to such stimuli (Rehbinder, 1990). In breeding practice, equal importance is ascribed to the general animal health status, proper nutrition, and achieving the appropriate bodyweight (Fennessy et al., 1991). Bodyweight, especially in young animals (Fennessy et al., 1991), determines future reproductive 
success and development (Gómez, 2004; Landete-Castillejos et al., 2007; Gómez et al., 2008; Dryden, 2016). When favourable environmental conditions ensure the good health of young deer, fawns may start to mature up to two months earlier than normal. In contrast, adverse conditions can delay maturation significantly, even into the third or fourth year of life (Asher \& Cox, 2013). A strong response to stress has a negative effect on the gastrointestinal function and reduces feed conversion considerably. This was confirmed in studies conducted on stressor-exposed reindeer calves, which exhibited substantially lower bodyweight gains than the control group (Reimers, 1972). Similarly, a significant negative correlation between cortisol level and growth rate was shown in cattle (Purchas et al., 1980). Hence, resistance to stress has been considered one of the main determinants of animal growth and development (Rehbinder et al., 1982; Rehbinder, 1990). Additionally, exposure to stressors impairs the immune system, which is associated with the risk of infectious diseases. Such immunological disorders contribute to suppression of gut microbiota (Simensen et al., 1980; Kelly, 1980; Riley, 1981; Griffin, 1989; Garber et al., 2020; Shi et al., 2019) and parasitological infections (De la Peña et al., 2020), which affect animal productivity negatively. An elevated glucocorticoid level is an important factor in stimulating bone tissue resorption and inhibiting the osteogenesis processes (Hillman et al., 1973; Kleerekoper et al., 1997).

The levels of cortisol and testosterone in European red deer and fallow deer have a significant effect on antler growth (Bartoš \& Bubenik, 2011; Bartoš et al., 2009). Suttie et al. (1992) and Ingram et al. (1999) reported significantly higher plasma cortisol levels during the intensive growth of new antlers and mineralization in late summer. Cortisol levels in plasma reflect the immediate physiological state (Sheriff et al., 2011), whereas faeces provide information about the endocrine state before sample collection (Palme et al., 2005), and hair is supposed to reflect the endocrine status in the prior weeks (Russell et al., 2012; He et al., 2014). Fallow deer are the species that is bred most often on Polish farms (FEDFA, 2020) and these investigations may be useful to breeders. The aim of the study was therefore to demonstrate the relationship between plasma cortisol level, bodyweight, and antler size in farmed male fallow deer (Dama dama) in various age groups and to assess the level of stress that affected the animals during routine rearing treatments.

\section{Materials and Methods}

The research was carried out at the research station of the Institute of Parasitology, Polish Academy of Sciences, Kosewo Górne (region of Warmia and Mazury, Poland) $\left(53^{\circ} 48\right.$ ' N, $\left.21^{\circ} 23^{\prime} \mathrm{E}\right)$. All analyses were performed with the consent of the Local Ethics Committee 0069, Resolution No. 42/2016. The study involved 33 fallow deer stags divided into three age groups, each containing 11 animals in separate pens, namely group I: one year old, group II: three years old, and group III: four and five years old. The animals were divided into these groups, because male deer reach physical maturity and maximum bodyweight at four years old. Each group had the same grazing conditions in summer (from May to September). The animals were provided with adequate space, food, and water ad libitum during grazing (DEFRA, 2020; FEDFA, 2020; Mattiello, 2009).

Measurements and blood collection were performed while the fallow deer were standing inside small handling boxes $(2 \mathrm{~m} \times 2 \mathrm{~m} \times 0.4 \mathrm{~m})$ with no need for sedation (García et al., 2002; Gáspar-López et al., 2011) in May in the third or fourth month of antler growth, and in September, before the rut during routine husbandry procedures. To determine the cortisol concentration, 5-ml blood samples were collected in vacuum tubes containing an anticoagulant agent (EDTA). The samples were chilled $\left(4-8{ }^{\circ} \mathrm{C}\right)$ within 15 minutes of collection. Plasma for analysis of the biochemical parameters was obtained by centrifuging whole blood at $3000 \mathrm{rpm}$ for 10 min with a laboratory centrifuge MPW-350R (MPW Medical Instruments, Warsaw, Poland) at $4{ }^{\circ} \mathrm{C}$. The blood plasma was frozen and kept at $-25^{\circ} \mathrm{C}$ until analysis. The cortisol concentration was determined with an enzyme immunoassay kit (Immulite 2000 Cortisol, Siemens, UK) according to the manufacturer's instructions. At the time of blood sampling, the bodyweight of the animals and the antlers in the group I animals were measured (Tajchman et al., 2020). In accordance with the routine zootechnical practice adopted on the farm, antlers of animals in groups II and III were cut at a height of $1 \mathrm{~cm}$ above the rose. After removal of dried velvet and mineral impurities and air-drying (in natural conditions) for 30 days, the antlers were weighed on an electronic balance with an accuracy of $+/-0.5 \mathrm{~g}$ (WLC F1/K, Radwag, Poland). The data represent the mean value of both beams of an individual.

The data were compiled, and analyses were carried out with Statistica 9.1 software (TIBCO Software Inc., Palo Alto, California, USA). The normality of the distribution of variables in the groups was verified with the Shapiro-Wilk test. The significance of changes in the level of cortisol between measurements was assessed with the Wilcoxon signed-rank test. The differences in cortisol concentration and changes in cortisol value and in bodyweight in the age groups were assessed using analysis of variance (ANOVA). The differences in antler weight in the age groups were assessed with the student T-test. The correlation of the bodyweight, weight gain, and length and weight of antlers with the cortisol level and its change were 
assessed with Spearman's rank correlations. A significance level of $P \leq 0.05$ was assumed, which indicated the presence of statistically significant differences or correlations.

\section{Results and Discussion}

Statistically significant differences were found between hormone levels in May and September ( $P$ $=0.04$ and $P=0.012$, ) and changes in the cortisol concentration $(P=0.023)$ between measurements. At the first hormone determination of level (May), a statistically significant difference was noted between groups I and II $(P \leq 0.05)$ and between group I and III) $(P \leq 0.05)$. No significant differences were found between group II animals and the older group. In September statistically significant differences were demonstrated only between group I and group III $(P \leq 0.05)$. Additionally, a difference was noted between the youngest animals and group II $(P \leq 0.05)$. A significantly higher decline in the cortisol level was noted in group II than in group I males. There were no significant differences in the magnitude of changes in the hormone concentration between groups. At both times, the older animals had higher levels of cortisol (Table 1).

In May, significant differences between the groups were noted in their bodyweight (Table 1). In September, statistically significant differences in bodyweight were demonstrated only between the groups I and II (Table 1). Additionally, a statistically significant difference in the weight gain was noted for group I in comparison with groups II and III. Group III had significantly heavier antlers than group II (Table 1). Older deer had higher body and antler weight and bodyweights were greater in September than in May in all age groups. These results are not surprising, as bodyweight gain and antler weight increase with the age of deer (Sauer, 1984; Suttie et al., 1984; Strickland \& Demarais, 2000; De Young et al., 2006).

Table 1 Effects of age and season on plasma cortisol level, bodyweight and size of antler of fallow deer

\begin{tabular}{|c|c|c|c|c|c|c|}
\hline Variable & Season & $\begin{array}{l}\text { One year old } \\
\text { (I) }\end{array}$ & $\begin{array}{l}\text { Three years old } \\
\text { (II) }\end{array}$ & Older (III) & $P$-value & $\begin{array}{c}\text { Contrasts of age } \\
\text { classes }\end{array}$ \\
\hline \multirow{3}{*}{$\begin{array}{l}\text { Cortisol, } \\
\text { ug/dL }\end{array}$} & May & $2.783 \pm 0.116$ & $5.865 \pm 0.244$ & $5.135 \pm 0.178$ & 0.004 & \multirow{2}{*}{$\begin{array}{l}\text { I vs II: } P<0.01 \\
\text { I vs III: } P=0.03 \\
\text { I vs III: } P<0.01\end{array}$} \\
\hline & September & $2.472 \pm 0.091$ & $3.485 \pm 0.106$ & $4.507 \pm 0.187$ & 0.012 & \\
\hline & Change & $-0.311 \pm 0.117$ & $-2.379 \pm 0.235$ & $-0.628 \pm 0.111$ & 0.023 & \multirow{4}{*}{$\begin{array}{l}\text { I vs II: } P=0.03 \\
\text { I vs II: } P<0.01 \\
\text { I vs III: } P<0.01 \\
\text { II vs III: } P=0.01 \\
\text { I vs II: } P<0.01 \\
\text { I vs III: } P<0.01 \\
\text { I vs II: } P<0.01 \\
\text { I vs III: } P=0.01\end{array}$} \\
\hline \multirow{3}{*}{$\begin{array}{l}\text { Body } \\
\text { weight, kg }\end{array}$} & May & $31.409 \pm 0.115$ & $63.364 \pm 0.397$ & $68.727 \pm 0.491$ & $<0.001$ & \\
\hline & September & $44.318 \pm 0.327$ & $83.682 \pm 0.389$ & $87.318 \pm 0.629$ & $<0.001$ & \\
\hline & Change & $12.909 \pm 0.254$ & $20.318 \pm 0.424$ & $18.591 \pm 0.492$ & 0.001 & \\
\hline \multicolumn{2}{|c|}{ Antler length, cm } & $13.318 \pm 0.267$ & & & & \\
\hline \multicolumn{2}{|c|}{ Antler weight, g } & & $596.55 \pm 8.70$ & $1180.73 \pm 28.97$ & $<0.001$ & \\
\hline
\end{tabular}

The average serum concentration of cortisol was $4.594 \pm 0.417 \mu \mathrm{g} / \mathrm{dL}$ in May and $3.488 \pm 0.290$ $\mu \mathrm{g} / \mathrm{dL}$ in September. The difference in the plasma cortisol concentrations between May and September was $1.106 \pm 0.345 \mathrm{ug} / \mathrm{dL}(P<0.01)$ with an associated $95 \%$ confidence interval from -1.81 to -0.40 . Thus, cortisol levels decreased by $67.7 \%$ between the time that antler growth occurred and the rut.

There were statistically significant correlations between cortisol level and bodyweight in May $(P \leq 0.05)$ and in September $(P \leq 0.05)$ (Table 2). A significant relationship was demonstrated between cortisol level and bodyweight gain in May $(P \leq 0.05)$ (Table 2). Moreover, there was an inverse correlation between the weight gain of the animals and the change in cortisol concentration $(P \leq 0.05)$ (Table 3 ). Fallow deer with large fluctuations in cortisol experienced less weight gain. There was no effect of cortisol concentration on the antler length in group I males and on antler weight in groups II and III (Table 2). 
Table 2 Correlation of cortisol concentration in farmed fallow deer with bodyweight, bodyweight gain and antler size

\begin{tabular}{lccc}
\hline \multirow{2}{*}{ Variables } & \multicolumn{3}{c}{ Concentration of cortisol (ug/dL) } \\
\cline { 2 - 4 } & \multicolumn{1}{c}{ May } & September & Change \\
\hline May bodyweight, kg & $0.398, P=0.022$ & $0.377, P=0.031$ & $-0.094, P=0.602$ \\
September bodyweight, kg & $0.507, P=0.003$ & $0.385, P=0.027$ & $-0.206, P=0.248$ \\
Weight gain, kg & $0.500, P=0.003$ & $0.299, P=0.090$ & $-0.349, P=0.047$ \\
Antler length, cm & $-0.296, P=0.377$ & $-0.329, P=0.322$ & $0.238, P=0.481$ \\
Antler weight, g & $0.102, P=0.651$ & $0.283, P=0.202$ & $0.349, P=0.111$ \\
\hline
\end{tabular}

The results of the plasma cortisol determinations in farmed fallow deer agree with the ranges for male red deer reported by Bubenik and Bartoš (1993) and Ingram et al. (1999). Similarly, in experiments on cervids that were immobilized physically or chemically during blood sampling, cortisol levels were close to those determined in the current study (Jopson et al., 1990; Bubenik \& Bartoš, 1993; Goddard et al., 1994). The present results disagree with those reported by Gáspar-López et al. (2010). However, these results cannot be compared directly, because the study was carried out on Iberian red deer (Cervus elaphus hispanicus). The cortisol levels in group I were lower than in the older animals, but the values were similar to those shown by Carragher et al. (1997). However, evidence suggests that this might be confounded with the physiological effects of maturation with circulating cortisol levels increasing with age because of desensitization of the cortisol feedback loop (Sapolsky, 1991; Van Cauter et al., 1996; Pavitt et al., 2015). However, compared with group II, the increase in cortisol concentration in group III was insignificant only at the second period of determination.

Investigations conducted on male red deer (Cervus elaphus) in New Zealand (Goddart et al., 1994; Ingram et al., 1999; Konjević et al., 2016) and in Spain (Gáspar-López et al., 2010) showed that the average 24-hour plasma cortisol concentration was higher during antler growth than before, during and after the rut. The spike and amplitude of cortisol were significantly higher during intensive antler growth than in the other periods (Ingram et al., 1999; Bubenik \& Bartoš, 1993; Konjević et al., 2016). The present study confirmed that the level of cortisol in the deer was significantly higher during intensive antler growth than the values determined before the rut.

Antler growth in cervids is correlated with rapid weight gain and higher mean plasma cortisol concentration (Suttie et al., 1995; Ingram et al., 1999; Gáspar-López et al., 2010). This was confirmed by the present results. However, lower weight gain was observed in fallow deer with large fluctuations in cortisol concentration and vice versa.

In the present study, the fallow deer reached the highest bodyweight before the rut in September, compared with the period of antler growth in May, which was consistent with the results of other studies (Gáspar-López et al., 2010; Gáspar-López et al., 2011; Olguin et al., 2013; Dryden, 2016). The period of reproductive quiescence during which there is new antler growth and rapid weight gain has been associated with higher mean plasma cortisol concentrations while the breeding season is associated with lower adrenal activity (Ingram et al., 1999). However, the correlations of cortisol level with antler length and weight in either May or September were not different from zero in the present study.

Cortisol levels are accepted as an indicator of the magnitude of stress that is being experienced by an animal. Stress may not obligatorily be immunosuppressive. Immune activity can be enhanced in response to transient unpredictable stressors, especially in body areas that require immune protection (Martin, 2009). Additional blood biochemistry analyses could indicate whether fallow deer have elevated insulin and cholesterol levels during stress that may lead to the development of diseases. Moreover, the level of cortisol observed in this study was higher than that observed in wild deer (Ventrella et al., 2020), and even in deer that were harvested by hunting (Vilela et al., 2020). Thus, despite the short duration of stress that affected these animals that were being reared in captivity for sampling, the level of stress was considerable.

Bodyweight and plasma cortisol concentrations in cervids during spring and early summer have been found to be positively correlated with increased insulin levels (McMahon et al., 1997). However, some authors indicated that a simultaneous rise in the levels of insulin and cortisol increased the risk of systemic metabolic disorders (Suttie et al., 1989; Dallman et al., 1995). Investigations in a group of young cervids showed that chronic stress changed the cortisol concentration in their blood plasma and led to hepatic 
steatosis syndrome (Goddart et al., 1994; Hanlon et al., 1995). The importance of this problem was emphasized in other studies that demonstrated that it affected up to $80 \%$ of wild cervid populations (Morrow et al., 1979; Kapp et al., 1989; Nakagawa et al., 1997). However, increased live weight gain in summer compared with winter was recorded in all Arctic, boreal, and temperate deer studied so far (McEwan, 1968; Bandy et al., 1970; Pollock 1975; Asher 1993). Deer reduce their appetite voluntarily during winter (McEwan, 1968). The cycle of voluntary food intake and growth is known to be under photoperiodic control (Suttie \& Simpson, 1985).

\section{Conclusion}

The cortisol content in fallow deer blood was significantly higher during antler growth than during the rut. Fallow deer with large changes in cortisol concentration between these periods had lower weight gains. The cortisol level had no effect on the size of the antlers. Finally, cortisol levels were higher in adult males than in group I. Thus, calmer animals with lower cortisol fluctuations should be selected for breeding, which would contribute to greater stability of weight gain and antler growth.

\section{Acknowledgments}

The authors thank their colleagues from Research Station of Institute of Parasitology in Kosewo Górne for taking care of experimental animals.

\section{Authors' Contributions}

Conceptualization: KDz-M, KT, SK; methodology: KDz-M, KT, SK; formal analysis: $K T$, KDz-M; investigation: $M B$, KDz-M; original draft preparation: KDz-M, KT; review \& editing: KDzM, KT; supervision: KT.

\section{Conflict of Interest Declaration}

The authors declare there is no conflict of interest.

\section{References}

Asher, G.W., !993. Growth and feeding management of farmed fallow deer in New Zealand. In: G.W. Asher (ed). Proc. First World Forum on Fallow Deer Farming, Mudgee, NSW Australia.

Asher, G.W. \& Cox, N., 2013. The relationship between body mass and puberty in young red deer (Cervus elaphus) hinds: Evidence of early-life effects on permissive live-weight thresholds. Anim. Reprod. Sci. !43(1-4), 79-84. DOI: 10.1016/j.anireprosci.2013.10.013.

Bandy, P.J., Cowan, I.M. \& Wood, A.J., 1970. Comparative growth in four races of black-tailed deer (Odocoileus hemionus). Part I. Growth in body weight. Can. J. Zool. 48, 1401-1410. https://doi.org/10.1139/z70-238

Bartoš, L. \& Bubenik, G.A., 2011. Relationships between rank-related behavior, antler cycle timing and antler growth in deer: behavioural aspects. Anim. Prod. Sci. 51, 303-310. DOI: 10.1071/AN10195

Bartoš, L., Schams, D. \& Bubenik, G.A., 2009. Testosterone, but not IGF-1, LH, prolactin or cortisol, may serve as antlerstimulating hormone in red deer stags (Cervus elaphus). Bone 44, 691-698. https://doi.org/10.1016/j.bone.2008.12.004

Bubenik, G.A. \& Bartoš, L., 1993. Cortisol levels in red deer (Cervus elaphus) and fallow deer (Dama dama) after an acute ACTH administration. Can. J. Zool. 71, 2258-2261. DOI: 10.1139/z93-317

Carragher, J.F., Ingram, J.R. \& Matthews, L.R., 1997. Effects of yarding and handling procedures on stress responses of free-ranging red deer (Cervus elaphus). Appl. Anim. Behav. Sci. 51, 143-158. https://doi.org/10.1016/S01681591(96)01090-8

Dallman, M.F., Akana, S.F., Strack, A.M., Hansen, E.S. \& Sebastian, R.J., 1995. The neural network that regulates energy balance is responsive to glucocorticoids and insulin and also regulates HPA axis responsivity at a site proximal to CRF neurons. Ann. N.Y. Acad. Sci. 771, 730-742. https://doi.org/10.1111/j.1749-6632.1995.tb44724.x

De La Peña, E., Martín, J., Barja, I., Pérez-Caballero, R., Acosta, I. \& Carranza, J., 2020. Immune challenge of mating effort: steroid hormone profile, dark ventral patch and parasite burden in relation to intrasexual competition in male Iberian red deer. Integr. Zool. 15, 262-275. DOI:10.1111/1749-4877.12427

DEFRA., 2020. Code of recommendations for the welfare of farmed deer. ADLib Agricultural Document Library, University of Hertfordshire, United Kindom.

DeYoung, R.W., Demarais, S., Honeycutt, R.L., Gee, K.L. \& Gonzales, R.A., 2006. Social dominance and male breeding success in captive white-tailed deer. Wildlife Soc. Bull. 31, 131-136. https://doi.org/10.2193/00917648(2006)34[131:SDAMBS]2.0.CO;2

Dryden, G. McL., 2016. Nutrition of antler growth in deer. Anim. Prod. Sci. 56(6), 962-970. http://dx.doi.org/10.1071/AN15051

FEDFA., 2020. The Federation of European Deer Farmers Associations. https://www.fedfa.com/en/fedfamembers/\#1364.

Fennessy, P.F., Thomson, J.M. \& Suttie, J.M., 1991. Season and growth strategy in red deer. Evolutionary implications and nutritional management. In: I.A. Renecker \& R.J. Hudson (eds). Wildlife production: Conservation and sustainable development. University of Alaska, Fairbanks, AK, USA. Pp. 495-501. 
Garber, A., Hastie, P. \& Murray, J.A., 2020. Factor influencing equine gut microbiota: Current knowledge. J. Equine Vet. Sci. 88, 102943. DOI: 10.1016/j.jevs.2020.102943

García, A.J., Landete-Castillejos, T., Garde, J.J. \& Gallego, L., 2002. Reproductive seasonality in female Iberian red deer (Cervus elaphus hispanicus). Theriogenology 8656, 1-10. DOI: 10.1016/s0093-691x(02)01048-8

Gáspar-López, E., Landete-Castillejos, T., Estevez, J.A., Ceacero, F., Gallego, L. \& Garcia, A.J., 2010. Biometrics, testosterne, cortisol and antler growth cycle in lberian red deer stags (Cervus elaphus hispanicus). Reprod. Domest. Anim. 45, 243-249. DOI:10.1111/j.1439-0531.2008.01271.x

Gáspar-López, E., Landete-Castillejos, T., Estevez, J.A., Ceacero, F., Gallego, L. \& Garcia, A.J., 2011. Seasonal variations in red deer (Cervus elaphus) hematology related to antler growth and biometric measurements. J. Exp. Zool. 315, 242-249. DOI: 10.1002/jez.670

Goddard, P.J., Rhind, S.M., Hamilton, W.J., MacDonald, A.J., Fawcett, A.R., Soanes, C. \& McMillen, S.R., 1994. The adrenocorticotrophic hormone stimulation test: Its potential use and limitations in red deer (Cervus elaphus). Can. J. Zool 72, 1826-1830. DOI: 10.1139/z94-246

Gómez, J.A., 2004. Crecimiento corporal y desarrollo de la cuerna hasta los dos aň os y medio de vida en el ciervo ibérico (Cervus elaphus hispanicus). Factores condicionantes. Ph.D. thesis, University of Castilla-La Mancha, Albacete, Spain.

Gómez, J.A., Landete-Castillejos, T., García, A.J., Gáspar-López, E., Estevez, J.A. \& Gallego, L., 2008. Lactation growth influences mineral composition of first antler in Iberian red deer Cervus elaphus hispanicus. Wildlife Biol. 14, 331338. DOI:10.2981/0909-6396(2008)14[331:LGIMCO]2.0.CO;2.

Griffin, J.F.T., 1989. Stress and immunity: A unifying concept. Vet. Immunol. Immunopathol. 20, 263-312. DOI: 10.1016/0165-2427(89)90005-6

Hanlon, A.J., Rhind, S.M., Reid, H.W., Burrells, C. \& Lawrence, A.B., 1995. Effects of repeated changes in group composition on immune response behaviour, adrenal activity and lightweight gain on farmed red deer yearlings. Appl. Anim. Behav. Sci. 44, 57-64.

He, L., Wang, W.X., Li L.H., Liu, B.Q., Liu, G., Liu, S.Q., Qi, L. \& Hu D.F., 2014. Effects of crowding and sex on fecal cortisol levels of captive forest musk deer. Biol. Res. 47, 48. https://doi.org/10.1186/0717-6287-47-48

Hillman, J.R., Davis, R.W. \& Abdelbaki, Y.Z., 1973. Cyclic bone remodeling in deer. Calcif. Tissue Res. 2, 323-330.

Ingram, J.R., Crockford, J.N. \& Matthews, L.R., 1999. Ultradian, circadin and seasonal rhythms in cortisol secretion and adrenal responsiveness to ACTH and yarding in unrestrained red deer (Cervus elaphus) stags. J. Endocrinol. 162, 289-300 DOI: 10.1677/joe.0.1620289.

Janiszewski, P., Bogdaszewski, M., Murawska, D. \& Tajchman, K., 2016. Welfare of farmed deer - practical aspects. Pol. J. Natur. Sci. 31(3), 345-361.

Jopson, N.B., Fisher, M.W. \& Suttie, J.M., 1990. Plasma progesterone concentrations in cycling and in ovariectomized red deer hinds: The effect of progesterone supplementation and adrenal stimulation. Anim. Reprod. Sci. 23, 61-73 https://doi.org/10.1016/0378-4320(90)90016-9

Kapp, P., Gaes, T. \& Bugar, J., 1989. Development of a fatty liver syndrome in stags during the rutting period. Magy. Allatorvosok 44, 151-155.

Kelly, K.W. 1980. Stress and immune function: A bibliographic review. Ann. Rech. Vet. 11, 445-478. https://pubmed.ncbi.nlm.nih.gov/7039471/

Kleerekoper, M., Schiebinger, R. \& Gutai, J.P., 1997. Steroid therapy for adrenal disorders - getting the dose right. J. Clin. Endocrinol. Metab. 82, 3923-3925. https://doi.org/10.1210/jcem.82.12.4473

Konjević, D., Janicki, Z., Slavica, A., Severin, K., Krapinec, K., Želježić, D. \& Božić, F. 2016. Monitoring cortisol metabolites in the faeces of captive fallow deer (Dama dama L.). Vet. Arh. 86, 363-371. https://hrcak.srce.hr/161235

Landete-Castillejos, T., Currey, J.D., Estévez, J.A., Gáspar-López, E., García, A.J. \& Gallego, L., 2007. Influence of physiological effort of growth and chemical composition on antler bone mechanicals properties. Bone, 41(5), 794803. DOI: 10.1016/j.bone.2007.07.013. PMID:17822969.

Martin, L.M., 2009. Stress and immunity in wild vertebrates: Timing is everything. Gen. Comp. Endocrinol. 163 (1-2), 70 76. https://doi.org/10.1016/j.ygcen.2009.03.008

Mattiello, S., 2009. Welfare issues of modern deer farming. Ital. J. Anim. Sci. 8, $205-217$. https://doi.org/10.4081/ijas.2009.s1.205

McEwan, E.H., 1968. Growth and development of barren-ground caribou. II. Postnatal growth rates. Can. J. Zool. 46, 1023-1029. https://doi.org/10.1139/z68-143

McMahon, C.D., Corson, I.D., Littlejohn, R.P., Stuart, S.K., Veenvliet, B.A. \& Suttie, J.M., 1997. Effects of season, protein and nutritional state on glucose tolerance during an annual cycle of growth in young red deer stags. J. Endocrinol. 154, 275-283. DOI: 10.1677/joe.0.1540275

Morrow, D.A., Hillman, D., Dade, A.W. \& Kitchen, H., 1979. Clinical investigation of a dairy herd with the fat cow syndrome. J Am Vet Med Assoc 174, 161-167.

Möstl, E. \& Palme, R., 2002. Hormones as indicators of stress. Domest. Anim. Endocrinol. 23, 67-74. https://doi.org/10.1016/S0739-7240(02)00146-7

Nakagawa, H., Oikawa, S., Oohashi, T. \& Katoh, N., 1997. Decreased serum lecithin: Cholesterol acyltransferase activity in spontaneous cases of fatty liver in cows. Vet. Res. Commun 21, 1-8 DOI: 10.1023/b:verc.0000009695.02015.20

Olguin, C.A., Landete-Castillejos, T., Ceacero, F., García, A.J. \& Gallego, L., 2013. Effects of feed supplementation on mineral composition, mechanical properties and structure in femurs of lberian red deer hinds (Cervus elaphus hispanicus). PLoS ONE 8, e65461. DOI: 10.1371/journal.pone.0065461 
Palme, R., Rettenbacher, S., Touma, C., El-Bahr, S.M. \& Möstl, E., 2005. Stress hormones in mammals and birds: Comparative aspects regarding metabolism, excretion, and noninvasive measurement in fecal samples. Ann. N.Y. Acad. Sci. 1040, 162-171. DOI: 10.1196/annals.1327.021

Pavitt, A.T., Walling, C.A., Möstl, E., Pemberton, J.M. \& Kruuk, L.E., 2015. Cortisol but not testosterone is repeatable and varies with reproductive effort in wild red deer stags. Gen. Comp. Endocrinol. 222, 62-68. DOI: https://doi.org/10.1016/j.ygcen.2015.07.009

Pollock, A.M., 1975. Seasonal changes in appetite and sexual condition in red deer stags maintained on a six-month photoperiod. J. Physiol. 244, 95P-96P.

Purchas, R.W., Barton, R.A. \& Kirton, A.H., 1980. Relationships of circulating cortisol levels with growth rate and meat tenderness of cattle and sheep. Aust. J. Agric. Res. 31, 221-232. DOI: https://doi.org/10.1071/AR9800221

Ranabir, S. \& Reetu, K., 2011. Stress and hormones. Indian J. Endocrinol. Metab. 15(1), 18-22. DOI:10.4103/22308210.77573

Rehbinder, C., 1990. Management stress in reindeer. Rangifer 3, 267-288. https://doi.org/10.7557/2.10.3.868

Rehbinder, C., Edqvist, L.E., Lundström, K. \& Villafañe, F., 1982. A field study of management stress in reindeer (Rangifer tarandus L.). Rangifer 2, 2-21. https://doi.org/10.7557/2.2.2.404

Reimers, E., 1972. Growth in domestic and wild reindeer in Norway. J. Wildl. Manage. 36, 612-619. https://doi.org/10.2307/3799094

Riley, V., 1981. Psychoneuroendocrine influences on immunocompetence and neoplasia. Science 212, 1100-1109. https://doi.org/10.1126/science.7233204

Russell, E., Koren, G., Rieder, M. \& Van Uum, S., 2012. Hair cortisol as a biological marker of chronic stress: Current status, future directions and unanswered questions. Psychoneuroendocrinology 37, 589-601. DOI: 10.1016/j.psyneuen.2011.09.009

Sapolsky, R., 1991. Do glucocorticoid concentrations rise with age in the rat? Neurobiol. Aging 13, $171-174$. https://doi.org/10.1016/0197-4580(92)90025-S

Sauer, P.R., 1984. Physical characteristics. White-tailed deer: Ecology and management. In: L.K. Halls (ed). Stackpole Books, Harrisburg, Pennsylvania, USA. Pp. 73-90.

Shi, D., Bai, L., Qu, Q., Zhou, S., Yang, M., Guo, S., Li, Q. \& Liu, C., 2019. Impact of gut microbiota structure in heatstressed broilers. Poult. Sci. 98, 2405-2413. https://doi.org/10.3382/ps/pez026

Simensen, E., Laksesvela, B., Blom, A.K.C. \& Sjaastad, O.V., 1980. Effects of transportations, a high lactose diet and ACTH injections on the white blood cells count, serum cortisol and immunoglobulin $\mathrm{G}$ in young calves. Acta Vet. Scand., 21, 278-29.

Smith, S.M. \& Vale, W.W., 2006. The role of the hypothalamic-pituitary-adrenal axis in neuroendocrine responses to stress. Dialogues Clin. Neurosci. 8, 383-395. https://www.ncbi.nlm.nih.gov/pmc/articles/PMC3181830/

Sheriff, M.J., Dantzer, B., Delehanty, B., Palme, R. \& Boonstra, R., 2011. Measuring stress in wildlife: Techniques for quantifying glucocorticoids. Oecologia 166, 869-887. DOI: 10.1007/s00442-011-1943-y

Strickland, B.K. \& Demarais, S., 2000. Age and regional differences in antlers and body mass of white-tailed deer. J. Wildl. Manage. 64, 903-911. DOI: 10.2307/3803198

Suttie, J.M. \& Simpson, A.M., 1985. Photoperiodic control of appetite, growth, antlers and endocrine status of red deer. In: P.F., Femessy \& K.R. Drew (eds). Biology of deer production. The Royal Society of New Zealand, Wellington. [two authors before three, before four, etc.

Suttie, J.M., Lincoln, G.A. \& Kay, R.N., 1984. Endocrine control of antler growth in red deer stags. J. Experiment. Zool. 71, 7-15.

Suttie, J.M., Fennessy, P.F., Lapwood, K.R. \& Corson, I.D., 1995. Role of steroids in antler growth of red deer stags. J. Experiment. Zool. 271, 120-130. DOI: https://doi.org/10.1002/jez.1402710207

Suttie, J.M., Fennessy, P.F., Corson, I.D., Laas, F.J., Crosbie, S.F., Butler, J.H. \& Gluckman, P.D., 1989. Pulsatile growth hormone, insulin-like growth factors and antler development in red deer (Cervus elaphus scoticus) stags. J. Endocrinol. 121, 351-360. DOI: 10.1677/joe.0.1210351

Tajchman, K., Bogdaszewki, M. \& Kowalczuk-Vasilew, E., 2020. Effects of supplementation with different levels of calcium and phosphorus on mineral content of first antler, bone, muscle, and liver of farmed fallow deer (Dama dama). Can. J. Anim. Sci. 100, 17-26. DOI: dx.doi.org/10.1139/cjas-2018-0234

Tajchman, K., Bogdaszewki, M., Kowalczuk-Vasilew, E. \& Dąbrowski R., 2019. Impact of day length and total protein content in the diet farmed fallow deer (Dama dama) on their plasma mineral level and haematological indices. Appl. Ecol .Environ. Res. 17(6), 14729-14750. http://dx.doi.org/10.15666/aeer/1706_1472914750

Van Cauter, E., Leproult, R. \& Kupfer, D., 1996. Effects of gender and age of the levels and circadian rhythmicity of plasma cortisol. J. Clin. Endocrinol. Metab. 81, 2468-2473. DOI: 10.1210/jcem.81.7.8675562

Ventrella, D., Elmi, A., Bertocchi, M., Aniballi, C., Parmeggiani, A., Govoni, N. \& Bacci, M.L., 2020. Progesterone and cortisol levels in blood and hair of wild pregnant red deer (Cervus elaphus) hinds. Animals 10, 143. DOI: 10.3390/ani10010143

Vilela, S., de Silva, A.A., Palme, R., Ruckstuhl, K.E., Sousa, J.P. \& Alves, J., 2020. Physiological stress reaction in red deer induced by hunting activities. Animals 10(6), 1003. https://doi.org/10.3390/ani10061003 